\title{
Measurement of Breakdown Electric Field Strength for Vegetation and Hydrocarbon Flames
}

\author{
Kago Ernest Maabong*, Kgakgamatso Mphale, Douglas Letsholathebe, Samuel Chimidza \\ Department of Physics, University of Botswana, Gaborone, Botswana \\ Email: *mphalekm@mopipi.ub.bw
}

How to cite this paper: Maabong, K.E. Mphale, K., Letsholathebe, D. and Chimidza, S. (2018) Measurement of Breakdown Electric Field Strength for Vegetation and Hydrocarbon Flames. Journal of Electromagnetic Analysis and Applications, 10, $53-66$.

https://doi.org/10.4236/jemaa.2018.103004

Received: November 16, 2107

Accepted: March 18, 2018

Published: March 21, 2018

Copyright (๑) 2018 by authors and Scientific Research Publishing Inc. This work is licensed under the Creative Commons Attribution International License (CC BY 4.0).

http://creativecommons.org/licenses/by/4.0/

\begin{abstract}
A significant number of fire-induced power disruptions are observed in several countries every year. The faults are normally phase-to-phase short circuiting or conductor-to-ground discharges at mid-span region of the high-voltage transmission system. In any case, the wildfire plumes provide a conductive path. The electrical conductivity is due to intense heat in combustion zone of the fire which creates ion and electrons from flame inherent particulates. Increase in the ion concentration increases the electrical conductivity of the fire plume. The main purpose of this study was to measure dielectric breakdown electric field for vegetation and hydrocarbon flames. The experimental data is needed for validation of simulation schemes which are necessary for evaluation of power grid systems reliability under extreme wildfire weather conditions. In this study, hydrocarbon and vegetation fuels were ignited in a cylindrically shaped steel burner which was fitted with type-K thermocouples to measure flame temperature. The fuels consisted of dried weeping wattle (Peltophorum africanum) litter, butane gas and candle wax. Two pinned copper electrodes supported by retort stands were mounted to the burner and energized to a high voltage. This generated a strong electric field sufficient to initiate dielectric breakdown in the flames. Breakdown electric field strength $\left(E_{\text {crit }}\right)$ obtained from the experiment decreased from 10.5 to $6.9 \mathrm{kV} / \mathrm{cm}$ for the flames with temperature range of 1003 to $1410 \mathrm{~K}$, respectively.
\end{abstract}

\section{Keywords}

Fire, High Voltage Flashover, Flame Conductivity, Weakly Ionized Plasma, Thermal Ionization, Breakdown Electric Field Strength

\section{Introduction}

Over the last decade, Southern Africa has experienced significant socio-economic growth. To sustain the economic development in the region, there is necessity 
for reliability of electrical power supply. However, there has been an inadequate supply of the resource to sub-region and the demand for the resource is projected to be at 610,000 GWh by 2025 [1]. Furthermore, anticipated regional effects of climate change are likely to affect generation and supply of the resource. Climate models predict that Southern Africa will be hotter and drier by the end of the century [2]. The hot, dry climate promotes increase in plant litter fall and creates atmospheric conditions conducive to occurrence of frequent wildfires. The fires may burn under or in close proximity to high-voltage transmission lines causing power outages. In fact, a significant number of fire-induced power disruptions have been observed in several countries. For example, in South Africa, vegetation fires are responsible for about $22 \%$ of annual transmission line faults [3].

The faults are normally phase-to-phase short circuiting or conductor-to-ground discharges at mid-span region of the high-voltage transmission system. In any case, the wildfire plumes provide a conductive path [4]. Besides the loss of energy supply, conductor-to-ground flashover is also a safety concern for firefighters who may be within an arcing zone during suppression [5].

Several researchers acknowledge that temperature and ionization are major factors that influence to the fire-induced flashover [6] [7]. Furthermore, field experiments seem to suggest that flame conductivity plays major role in fire-induced flashover [8].

It is intended in the study to: 1) measure dielectric breakdown electric field for vegetation and hydrocarbon flames at atmospheric pressure; the experimental data is needed for validation of simulation schemes which are necessary for evaluation of power grid systems reliability under extreme wildfire weather conditions; 2) simulate the parameter for flame at normal temperature gradient. Even though the parameter has been measured for other types of flames, there are a lot of inconsistencies in values obtained from the experiments, e.g., in [4] and [9]. Furthermore, the parameter is crucial for initiation of streamers propagation in flames, an electrical discharge mechanism for conduction in fluids.

Electro-thermal properties of a gas dynamic boundary layer between electrodes and combustion plasma are critical in conduction of electric current through the plasma. Increasing the applied potential on the electrode decreases the depth of the electrostatic sheath around the electrode, thereby increasing the probability of conduction through the plasma. Section 2 discusses relevant theory on the initiation of an electrical discharge from an energized electrode through the plasma. In the Section, the relation between critical breakdown electric field strength and electrode-plasma temperature gradient is derived from energy balance relation in the boundary layer adjacent to the electrode surface. It is then simulated for normal flame temperatures. A discussion on the experimental method to measure critical breakdown electric field strength is given in Section 3 of the manuscript. The results from the experiment are given and discussed in Sections 4. Conclusions and future research direction are given in the 
last Section of the manuscript.

\section{Theoretical Considerations}

\subsection{Critical Breakdown Electric Field Strength}

Consider two pin electrodes, separated by a distance " $d$ ", inserted in a weakly-ionized combustion plasma in thermal equilibrium (Figure 1). Suppose that the electrodes are air cooled and at a surface temperature $\mathrm{T}_{s}$ while that of the flame plasma is $T_{\mathrm{f}}$. As the combustion gases flow over the electrodes, a thin boundary layer is created adjacent to their surface. When the electrodes are energized, a thin plasma sheath is created within the boundary layer which is characterized by disparity in ion and electron concentration (Xu, 2014 [10]). If a strong positive potential is applied to one of the electrodes, electrons would drift from the bulk of the plasma into its sheath while positively charged ions would be repelled from the electrode. As the ions and electrons drift away and to the electrode, they collide with plasma neutral particulates resulting in joule heating in the boundary layer. Accounting for energy loss from the applied electric field into other fluxes (e.g. convection and conduction), gives an energy balance equation in the boundary layer as:

$$
\frac{\partial T}{\partial t}+\left(v_{g} \nabla\right) T=\frac{\lambda_{T}}{\rho_{g} C_{p}} \nabla^{2} T+\frac{\sigma}{\rho_{g} C_{p}} E^{2}
$$

where: $T, \rho_{g}, C_{p}, E, \lambda_{T}$ and $\sigma$ are plasma temperature, gas density, specific heat capacity, electric field strength, thermal and electric conductivity.

Under steady state conditions and noting that plasma gas flow is transverse to the direction of electric discharge (Figure 1), Equation (1) reduces to:

$$
\lambda_{T} \nabla^{2} T=\sigma E^{2}
$$

Integrating Equation (2) over electrode gap distance and across temperature gradient, (i.e., from; $x=0$ to $d$ and $T_{s}$ to $T_{f}$ ) gives the following relation (Messerle et al. [11]):

$$
\Lambda(1-\beta)=x d(1-\beta)
$$

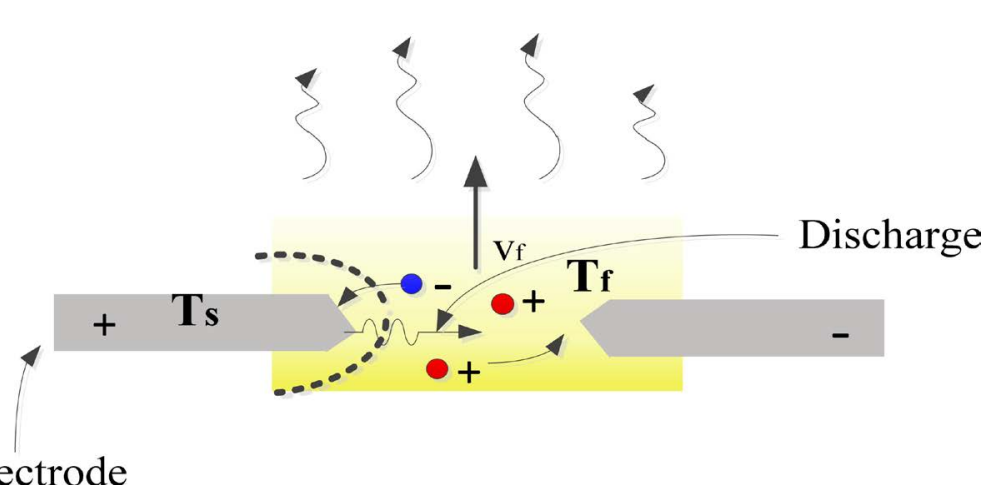

Figure 1. A schematic diagram showing electrode arrangement and sheath in the combustion plasma. 
where $\Lambda=\frac{2 \lambda_{T}}{\sigma E^{2}}\left(T_{f}-T_{s}\right)$ and $\beta=\frac{x}{d}$.

At breakdown, $d$ becomes small as the plasma sheath depth is reduced and consequently $\beta$ becomes large. Rearranging Equation (3) and simplifying gives:

$$
\Lambda=d^{2}
$$

where; $x=d$.

Following from (3) and (4), the critical electric field strength at breakdown is given by the expression:

$$
E_{\text {crit }}=\frac{1}{d} \sqrt{\frac{2 \lambda_{T}}{\sigma}\left(T_{f}-T_{s}\right)}
$$

\subsection{Simulation of Critical Electric Field Strength}

Simulation for the Ecrit was done to determine its expected range under normal flame conditions. A potassium-seeded hydrocarbon flame of the following temperature-dependent electro-physical properties was considered:

a) Electron $\operatorname{density}\left(N_{e}\right)$ :

The electron density in the flame was determined by using Saha equation for thermal ionization shown below as:

$$
N_{e}=\left(K_{1} N_{p}\right)^{1 / 2}\left[\left(1+\frac{K_{1}}{4 N_{p}}\right)^{1 / 2}-\left(\frac{K_{1}}{4 N_{p}}\right)^{1 / 2}\right] \mathrm{cm}^{-3}
$$

where $K_{1}$ and $N_{p}$ are as calculated in Mphale et al. [12].

b) Thermal conductivity:

Analytical expression for the thermal conductivity was derived from a linear fit of experimental data from Chandra et al. [13] and it is given as:

$$
\lambda_{T}=3.86 \times 10^{-5} \mathrm{~T}+0.08 \mathrm{~W} \cdot \mathrm{m}^{-1} \cdot \mathrm{K}^{-1}
$$

Pearson correlation coefficient $(r)$ for fit was 0.97 .

\section{c) Sheath depth:}

Chandra et al. [13] also give temperature related sheath depth values for seeded flames. An analytical expression for the depth was derived from a linear fitting procedure is given as:

$$
d=-1.91 \times 10^{-7} \mathrm{~T}+2.92 \times 10^{-4} \mathrm{~m}
$$

The Pearson correlation coefficient $(r)$ for fit was 0.98 .

Electrical conductivity of the combustion plasma to be determined from the relation [12]:

$$
\sigma=\frac{N_{e} q^{2}}{m_{e} \varphi_{e f f}} \mathrm{~s}^{-1}
$$

where $\varphi_{\text {eff }}$ is electron momentum transfer collision frequency. It is approximated to be $1 \times 10^{12} \mathrm{~s}^{-1}$, e.g. in Letsholathebe and Mphale. [14].

The critical electric field strength was simulated using Equation (5) for the normal combustion flame temperature. The simulated field strength is shown in 
Figure 2. In the figure, the highlighted (with an ellipse) shows estimated critical field strength for flames of interest in the experiment. The temperature measured from experiment were on average close the $1200 \mathrm{~K}$ temperature difference (i.e., $T_{f}-T_{s}$ ). The critical electric field strength for the flames was simulated to be $9.5 \mathrm{kV} / \mathrm{cm}$.

\section{Experimental Methods}

\subsection{Experimental Set Up}

Biomass and hydrocarbon fuels were ignited in a cylindrically shaped steel burner (Figure 3), which was fitted with Type-K thermocouples to measure flame temperature. The fuels consisted of dried weeping wattle (Peltophorum africanum) litter, butane gas and candle. Two pinned copper electrodes supported by retort stands were mounted to the burner and energized to high voltage (up to $10 \mathrm{kV}$ ) by a PHYWE ${ }^{\circledR}$ power supply. The purpose of the electrodes was to generate strong electric field sufficient to initiate dielectric breakdown in

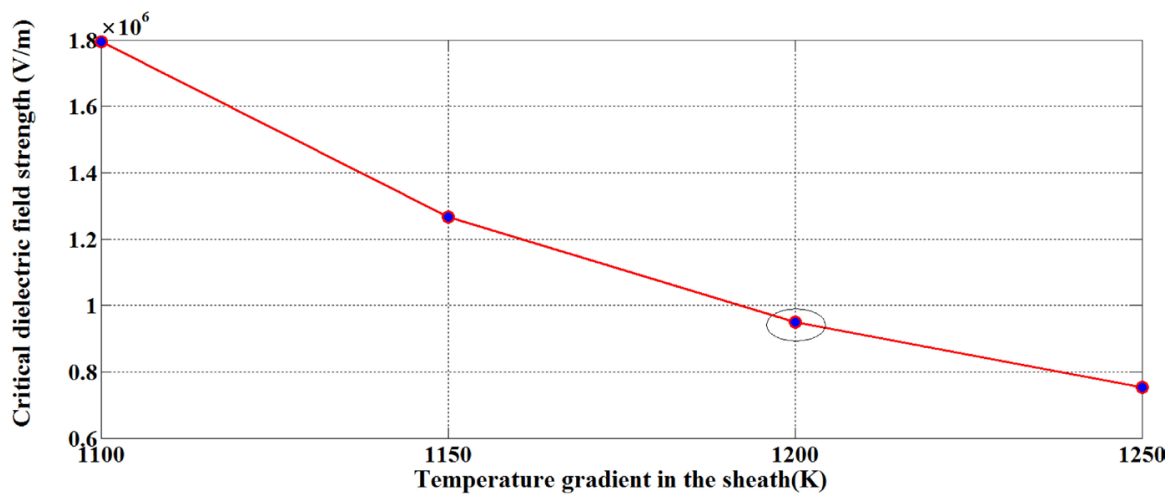

Figure 2. Simulated critical electric field strength for temperature range $1100-1250 \mathrm{~K}$.

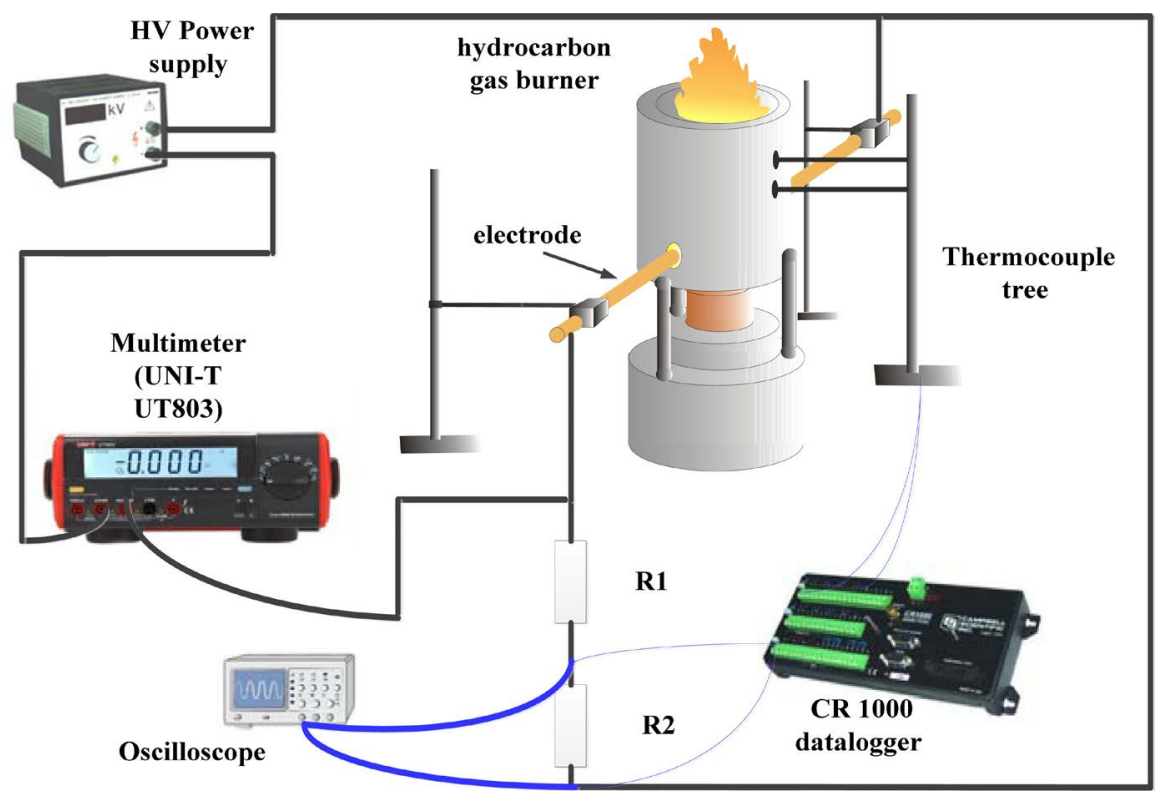

Figure 3. The schematic diagram for breakdown electric field measurement set up. 
the flames. The potential difference between the electrodes was increased at a steady rate of $0.2 \mathrm{kV}$ per 10 seconds until breakdown occurred. As the applied potential difference was increased, it was monitored through an oscilloscope. A sensitive multimeter (UNI-T UT 803) was used to measure current through the circuit during the experiment (Figure 3). Potential difference across resistor R2 (Figure 3) and thermocouples were wired to a Campbell Scientific CR1000 data logger for accurate determination of breakdown voltage.

\subsection{Combustion Fuels}

\subsubsection{Weeping Wattle Fuel Samples}

The biomass sample used in the experiment consisted of litter fall from Peltophorum africanum tree sampled randomly from an open woodland habitat in Mogoditshane (Kweneng District, Botswana). The tree is endemic to most parts of Southern Africa, mainly in wooded grasslands. It is known to contain reasonable amounts of macronutrient which includes; phosphorus, calcium, magnesium, sodium and potassium (Mongalo [15]). Moreover, Aganga and Mesho [16] analyzed that Peltophorum africanum contains an average of $1.53 \%$ and $1.4 \%$ of Calcium and Potassium on dry mass basis, respectively.

The litter fall was dried in the laboratory for about 5 days before it was burnt so as to improve combustion efficiency. Combustion of the plant matter is a complex process that depends on the amount of oxygen available and prevalent weather conditions. Jenkins et al. [17] estimate that it proceeds by the following reaction equation:

$$
\begin{aligned}
\mathrm{C}_{x 1} \mathrm{H}_{x 2} \mathrm{O}_{x 3} \mathrm{~N}_{x 4} \mathrm{~S}_{x 5} \mathrm{Cl}_{x 6} \mathrm{Si}_{x 7} \mathrm{~K}_{x 8} \mathrm{Ca}_{x 9} \mathrm{Mg}_{x 10} \mathrm{Na}_{x 11} \mathrm{P}_{x 12} \mathrm{Fe}_{x 13} \mathrm{Al}_{x 14} \mathrm{Ti}_{x 15} \\
+n_{1} \mathrm{H}_{2} \mathrm{O}+n_{2}(1+\mathrm{e})\left(\mathrm{O}_{2}+3.76 \mathrm{~N}_{2}\right) \\
\Rightarrow n_{3} \mathrm{CO}_{2}+n_{4} \mathrm{H}_{2} \mathrm{O}+n_{5} \mathrm{O}_{2}+n_{6} \mathrm{~N}_{2}+n_{3} \mathrm{CO}_{2}+n_{4} \mathrm{H}_{2} \mathrm{O}+n_{5} \mathrm{O}_{2} \\
\quad+n_{6} \mathrm{~N}_{2}+n_{12} \mathrm{HCl}+n_{13} \mathrm{KCl}+n_{14} \mathrm{~K}_{2} \mathrm{SO}_{4}+n_{15} \mathrm{C}+\cdots
\end{aligned}
$$

The first reactant in Equation (10) is an incomplete empirical formula for plant material [17]. Elemental composition in the formula varies for different types of plants. The equation depicts several by-products of the combustion or products of incomplete combustion (PICS) which are released into the atmosphere in form of a pyrocumulus cloud. Potassium $(\mathrm{K})$ species and graphitic carbon $\left(C_{n}\right)$ form a major fraction of the inorganic emissions into combustion zone from the thermally decomposing plant structure.

\subsubsection{Butane Gas}

Butane is a naturally occurring gaseous alkane which is produced from fractional distillation of crude oil. The chemical formula of the gas is $\mathrm{C}_{4} \mathrm{H}_{10}$. The fuel exists in two structural isomeric forms; normal butane ( $n$-butane) and iso-butane. The two isomers have a slightly different combustion characteristics and reaction rate when placed under similar combustion conditions (Wilk et al. [18]). Butane is an important component of modern fuels, e.g., in Liquefied Petroleum Gas (LPG), where it is mixed with propane and other gases. For commercial purpos- 
es, $n$-butane is commonly used. This is due to the fact that the gas is cheaper, cleaner and produces more energy than other combustion gas fuels of the same amount under same conditions.

In the experiment, pressurized $n$-butane contained in $190 \mathrm{~g}$ cartridge was used for its quiet, clean and controllable flame. When ignited in air adiabatic temperature of butane flame could reach about $1970^{\circ} \mathrm{C}$ (Ševčik et al. [19]). Under sufficient oxygen conditions, butane burns according to the following equation:

$$
2 \mathrm{C}_{4} \mathrm{H}_{10}+13 \mathrm{O}_{2} \Rightarrow 8 \mathrm{CO}_{2}+10 \mathrm{H}_{2} \mathrm{O}
$$

\subsubsection{A Candle}

A candle is an ignitable wick embedded in paraffin wax. The wax is a mixture of saturated straight-chained solid alkanes (i.e., hydrocarbons with a general formula given by $\mathrm{C}_{n} \mathrm{H}_{2 n+2}$ ). For a candle paraffin wax, $n$ ranges from 19 to 36 with an average value of 25 . The wick is often made from braided or twisted cotton fabric. On average, heat of combustion for a candle is $43.1 \mathrm{MJ} / \mathrm{kg}$ and it has been observed that the fuel is the safest sources of light and heat energy. A candle flame is of diffusion laminar type with temperature with temperature ranging from 600 to $1400^{\circ} \mathrm{C}$ (Gaydon and Wolfhard, [20]). The hottest part of the flame is in the outer part of complete combustion zone. According to Raju and T'ien [21], the combustion reaction of candle wax vapour (blended with steric acid) with air proceeds as follows:

$$
\begin{aligned}
& \mathrm{C}_{25} \mathrm{H}_{52}+0.31 \mathrm{C}_{18} \mathrm{H}_{36} \mathrm{O}_{2}+46.06\left(\mathrm{O}_{2}+3.76 \mathrm{~N}_{2}\right) \\
& \Rightarrow 30.58 \mathrm{CO}_{2}+31.58 \mathrm{H}_{2} \mathrm{O}+173.19 \mathrm{~N}_{2}
\end{aligned}
$$

There are different types of candles depending on the purpose for which they are used, e.g. tapper, votire. In the experiment, a tapper white wax Prices Lighthouse $^{\circledR}$ candle of diameter $2.0 \mathrm{~cm}$ and height $25.0 \mathrm{~cm}$ was used. The combustion rate of the candles is estimated at $0.11 \mathrm{~g} / \mathrm{min}$ (Hammins and Bundey, [22]).

\subsection{Flame Temperature Measurement}

A thermocouple "tree" of about $20.0 \mathrm{~cm}$ high was constructed from steel rods of $2.0 \mathrm{~cm}$ diameter. A rectangular base $(10.0 \times 15.0 \mathrm{~cm})$ was wielded to the tree "stem" for it to stand firmly upright. Two side "arms" of length $10.0 \mathrm{~cm}$ were attached at positions; 10.0 and $14.0 \mathrm{~cm}$ from the tree base to hold two thermocouples. Thermocouples used were made from insulated chromel-alumel thermocouple wire $50 \mu \mathrm{m}$ in diameter. The thermocouple wire had shield which can withstand high temperatures. The type $\mathrm{K}$ thermocouple wires were then electrofused at one end to make perfect junction (bead). The thermocouples were calibrated using a hot air gun and a multimeter. They were then fixed to the tree "arms" by means of a muffler tape and the junctions were left protruded $1 \mathrm{~cm}$ beyond the "arm" length into the flame. The thermocouples were then wired to Campbell Scientific CR $1000^{\circledR}$ data logger to read in the temperatures in to a computer throughout each experiment. 


\subsection{Breakdown Voltage Measurement}

Two copper electrodes of diameter $0.80 \mathrm{~cm}$ were sharpened to hemispherical tips of diameter $0.06 \mathrm{~cm}$ and used to generate an intensified electric field within the fuel flames. They were mounted to the steel cylindrical burner through $1.20 \mathrm{~cm}$ diametrically oppose holes. This allowed the distance between them to be varied. The electrodes were held in position by insulated retort stand clamps. A positive terminal of a PHYWE ${ }^{\circledR}$ high voltage dc power supply was connected to one electrode while its negative terminal was connected to the other. The power supply had the capacity to produce $10 \mathrm{kV}$ potential difference. The power supply had a current surge protector. A circuit diagram which shows experimental set up is shown in Figure 4. During combustion of the fuels, the potential difference between the electrodes was varied by increasing output voltage from the power supply at a constant rate of $0.2 \mathrm{kV}$ every 10 seconds. As the potential difference between the electrodes was raised, its accurate value was recorded and observed in the data logger and Cathode Ray Oscilloscope, respectively. At breakdown voltage, a sudden increase in current is registered in the sensitive millimetre (shown in Figure 4) as the flame becomes conductive. There is also a sudden drop in potential difference across $\mathrm{R} 2$ as the load becomes less resistive.

\section{Results and Discussions}

\subsection{Flame Temperatures}

Flames up to $20 \mathrm{~cm}$ high were observed during the combustion of Peltophorum africanum litter as air entrained through the holes of the cylindrical burner to facilitate near-efficient combustion. The flames from the combustion of litter took 60 - 80 seconds to extinguish while flame from other fuels persisted for more than 250 seconds. It took 40 seconds for Peltophorum africanum flames to fill the space inside the burner. The flame reached its maximum temperature of $1022 \mathrm{~K}$ after 50 seconds. Temperatures measured at the fuel-flame interface during combustion of the three fuels are shown in Figure 5.

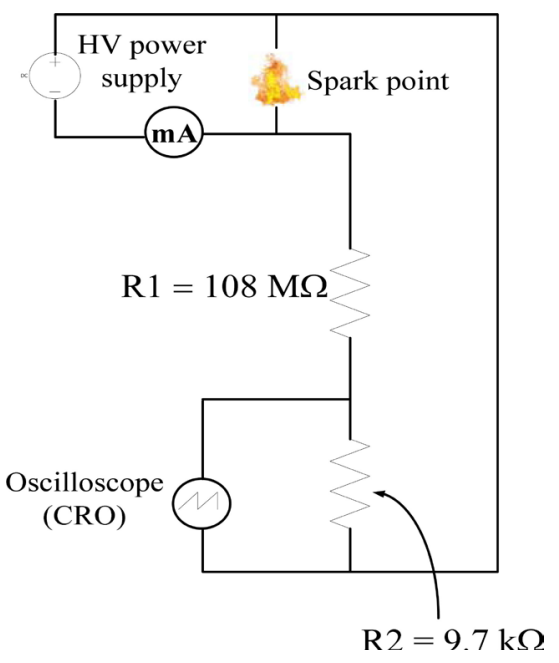

Figure 4. The circuit diagram for the experiment. 
It was observed from Figure 5 that the butane flame temperature rose rapidly as it burnt fiercely to a temperature of $1230 \mathrm{~K}$ in 10 seconds. There was no observable soot emission from the flame during combustion. Immediately after 10 seconds, the butane flame temperature rose at a very slow rate to a maximum of $1471 \mathrm{~K}$ which occurred after 120 seconds. It then continued at an average value of about $1405 \mathrm{~K}$ until the burner was switched off.

As for the candle flame, its temperature was observed to rise rapidly to reach a maximum of $988 \mathrm{~K}$ in $45 \mathrm{~s}$. It then decreased steadily to a minimum of $656 \mathrm{~K}$ at 75 seconds after ignition as the flame was deflected away from the thermocouple bead. It was noted that there was no wind that initiated the flame deflection. This occurred just before dielectric breakdown. Thereafter, the flame temperature rose to a maximum of $914 \mathrm{~K}$ at 100 seconds after ignition and continued to burn at an average of $771 \mathrm{~K}$ until the candle flame was extinguished.

It took longer for Peltophorum africanum flame to reach its maximum temperature compared to the other fuels as flaming depended on the time taken for volatilization of flammable pyrolysates to occur. The vegetative material has to thermally decompose first for ignition to occur.

\subsection{Breakdown Voltage}

\subsubsection{Butane Gas}

At about 65 seconds after the butane fuel was ignited, high voltage dc was applied to one the pinned electrodes at a steady rate $0.02 \mathrm{kV}$ per second. This generated electric field strength between the electrodes which was amplified due to the hemispheric shape of the electrode tip. The electric field produced by the pinned electrodes $\left(E_{p p}\right)$ is given by the expression:

$$
E_{p p}=\frac{V_{p}}{\ln \left\{\frac{\left(1+\eta_{0}\right)}{\left(1-\eta_{0}\right)}\right\}}\left(\frac{a}{\left(a^{2}-x^{2}\right)}\right)
$$

where

$$
\eta_{0}=\left(\frac{d / 2}{(d / 2)+R}\right)^{1 / 2}
$$

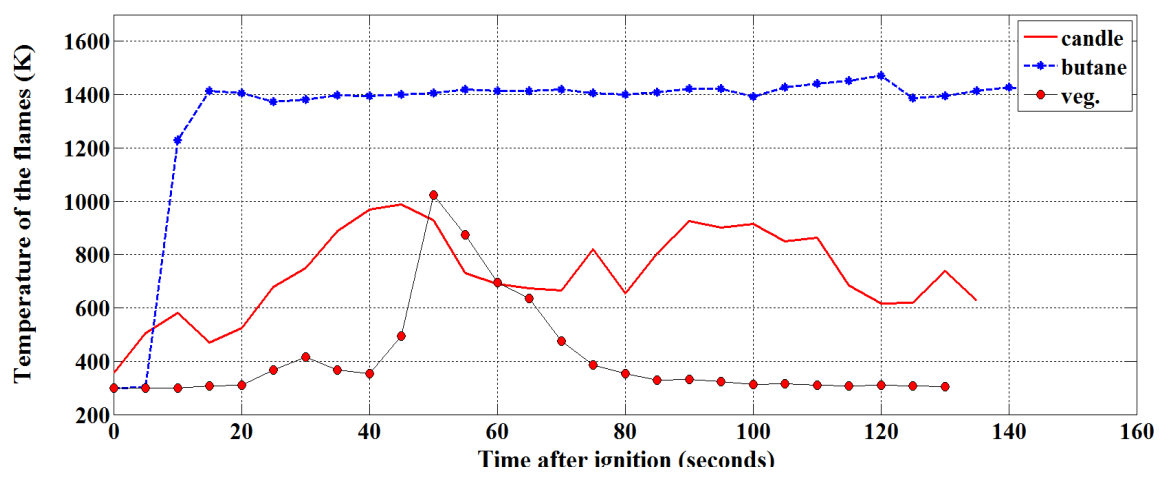

Figure 5. Flame temperature variation with time during combustion of the fuels. 


$$
a=((d / 2)((d / 2)+R))^{1 / 2}
$$

$R=$ radius of curvature for the tip;

$d=$ inter electrode gap.

It was observed that the potential difference was rising at the steady rate up to 140 seconds after ignition. This was the times at which breakdown occurred. The breakdown voltage $\left(V_{\text {crit }}\right)$ was determined from potential difference across $R 2$ (Figure 4) which was recorded in the data logger. It was calculated from the relation:

$$
V_{\text {crit }}=\left\{(R 1 / R 2) \times V 2_{\text {crit }}\right\}
$$

where: $R 1=108.2 \mathrm{M} \Omega$;

$$
\begin{aligned}
& R 2=9.7 \mathrm{k} \Omega ; \\
& V 2_{c r i t}=\text { potential difference across } R 2 \text { at breakdown. }
\end{aligned}
$$

As it is shown in Figure 6, the breakdown voltage for butane gas was determined to be $2.397 \mathrm{kV}$. Inter-electrode gap distance was $0.22 \mathrm{~cm}$. The variation of potential difference between the electrodes with time is shown in the figure.

\subsubsection{Candle Flame}

At about 10 seconds from the ignition time, high voltage dc was applied to pin copper electrodes separated by a distance of $0.14 \mathrm{~cm}$. When the potential difference was applied at the rate of $0.3 \mathrm{kV}$ per second after 10 seconds, it took 65 seconds for breakdown to occur (Figure 7). It occurred in the cool region of the flame where sooting was prevalent. This was after there was a slight deflection of flame. Ionization and cooler temperatures initiated the spark over as the soot particles are mostly positively charged.

The voltage across R2 decreased at a steeper rate until it reached value of 354 $\mathrm{mV}$ after 85 seconds since ignition. After 90 seconds, there was a decrease of potential difference across $\mathrm{R} 2$ at an average rate of $5.5 \mathrm{mV} / \mathrm{s}$ until after 115 seconds. A very small potential difference was recorded soon after 120 seconds.

\subsubsection{Weeping Wattle Flame}

When a high voltage dc potential difference was applied to pin copper electrodes

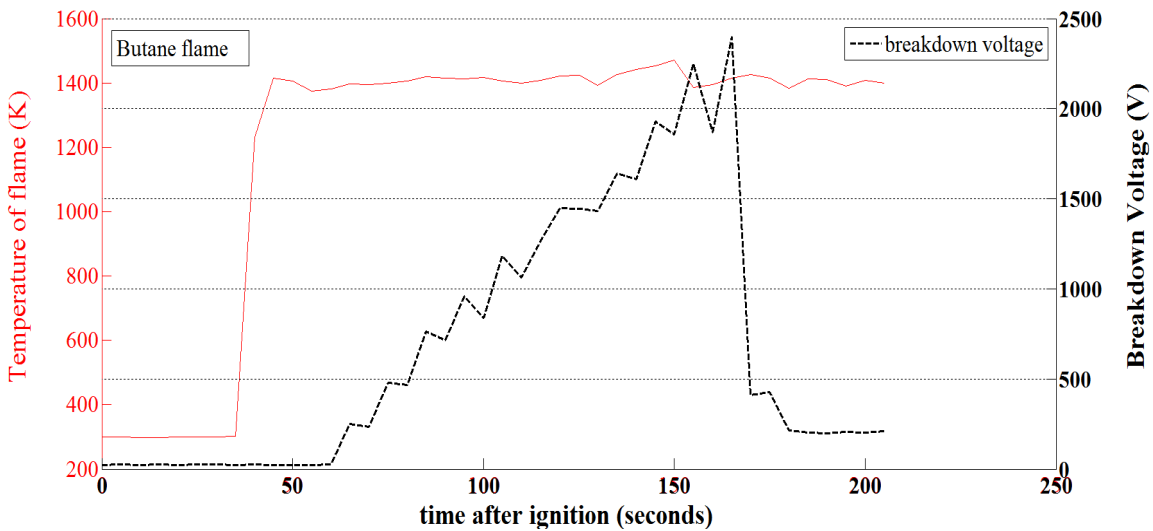

Figure 6. Variation of: (a) potential difference between electrodes and (b) temperature in butane flame with time. 


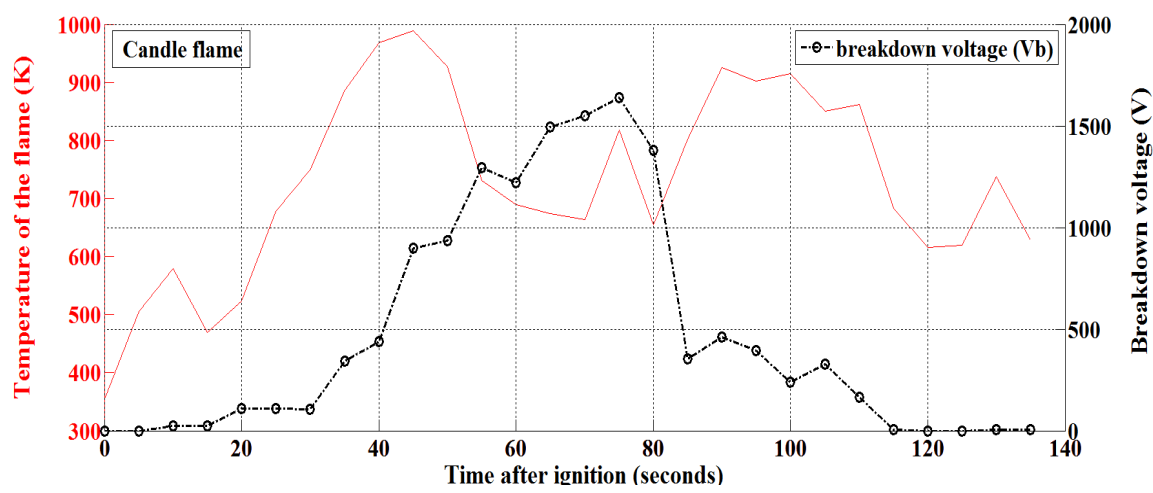

Figure 7. Variation of: (a) potential difference between electrodes and (b) temperature in candle flame with time.

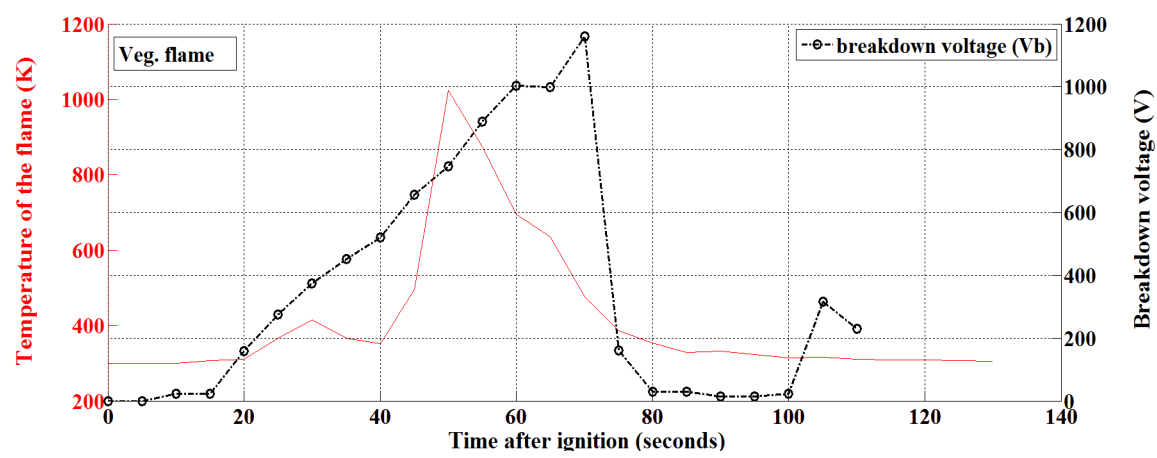

Figure 8. Variation of: (a) potential difference between electrodes and (b) temperature in candle flame with time.

separated by a distance of $0.06 \mathrm{~cm}$ in vegetation litter flame at a constant rate of $0.2 \mathrm{kV}$ per 10 seconds, a breakdown voltage of $1.120 \mathrm{kV}$ was obtained (Figure 8). It took 70 seconds to attain the breakdown voltage. It occurred at approximately 20 seconds after maximum temperature was obtained. This could be attributed to soot formation in the flame which is believed contribute to flashover in such flames, e.g., in Wang et al. [23].

After the breakdown voltage, the potential difference across R2 decreased at a steeper rate until it reached value of $15 \mathrm{mV}$ after 90 seconds after ignition. There was a steady small decrease in potential difference across R2 between 80 and 100 seconds. A small jump in the potential was observed thereafter.

\subsection{Breakdown Electric Field Strength}

From the above observations, breakdown electric field strength for the flames were calculated using distances between electrodes. It was observed that separation distances between electrodes were: $0.06,0.14$ and $0.22 \mathrm{~cm}$ for vegetation litter, candle and butane flames, respectively. The calculated breakdown electric fields are shown in Figure 9. They have been determined to be 10.5, 7.9 and $6.9 \mathrm{kV} / \mathrm{cm}$.

\section{Conclusion}

The measurement of dielectric breakdown for the vegetation and hydrocarbon 


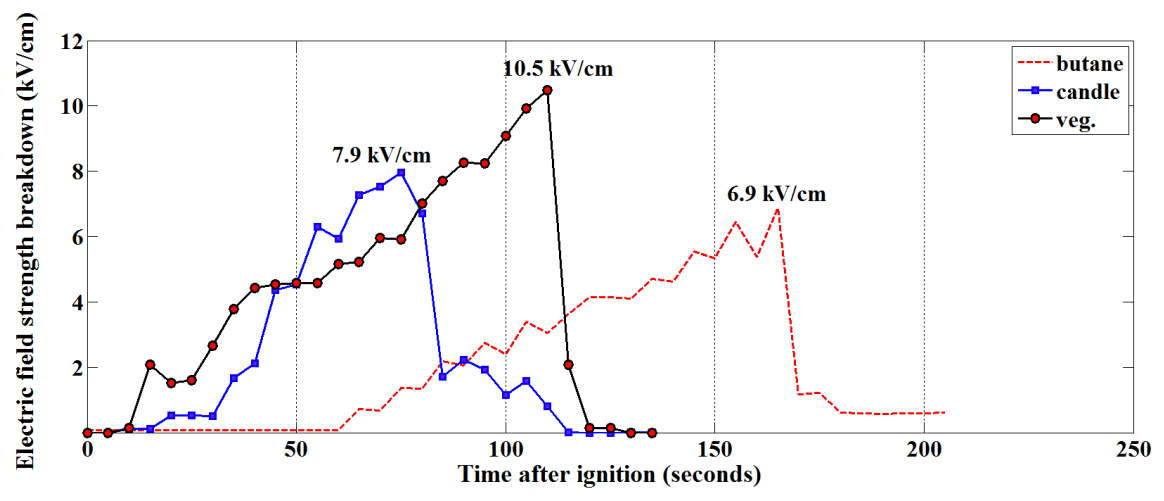

Figure 9. Variation of breakdown dielectric field strength with time after ignition.

flames has been performed using the pin electrodes. The pin electron enhanced the electric field in the flame gap so much that the conduction occurred at lower potential differences compared to other procedures e.g., using parallel plates. The maximum potential difference applied between the electrodes was $2.2 \mathrm{kV}$. The dielectric breakdown electric field strength for the flames ranged from 6.9 to $10.5 \mathrm{kV} / \mathrm{cm}$ for maximum temperatures of 1400 to $1003 \mathrm{~K}$, respectively. Of the flames considered, vegetation flame had the highest dielectric breakdown electric strength even though its maximum temperature was slightly higher than that of candle flame. This was because of the effect of soot which has bridged the spark gap.

\section{References}

[1] Spalding-Fecher, R., Senatla, M., Yamba, F., Lukwesa, B., Himunzowa, G., Heaps, C., Chapman, A., Mahumane, G., Tembo, B. and Nyambe, I. (2017) Electricity Supply and Demand Scenarios for Southern Africa Power Pool. Energy Policy, 101, 403-414. https://doi.org/10.1016/j.enpol.2016.10.033

[2] Mphale, K., Adedoyin, A., Nkoni, G., Ramaphane G., Wiston, M. and Chimidza, S. (2017) Analysis of Temperature Data in Semi-Arid Botswana: Trends and Break Points. Meteorology and Atmospheric Physics, 1-24.

https://doi.org/10.1007/s00703-017-0540-y

[3] Minnaar, U.J., Gaunt, C.T. and Nicolls, F. (2012) Characterisation of Power Systems Events on South African Transmission Power Lines. Electric Power Systems Research, 88, 25-32. https://doi.org/10.1016/j.epsr.2012.01.015

[4] Robledo-Martinez, A. and Guzman, E. (1991) Dielectric Characteristics of a Model Transmission Line in the Presence of Fire. IEEE Transactions on Electrical Insulation, 26, 776-782. https://doi.org/10.1109/14.83702

[5] Mousa, A.M. (1990) Protecting Firemen against Fire-Induced Flashovers. IEEE Transactions on Power Delivery, 5, 297-302. https://doi.org/10.1109/61.107288

[6] You, F., Chen, H., Zhang, L., Zhang, Y., Zhou, J. and Zhu, J (2011) Experimental Study on Flashover of High Voltage Transmission Lines Induced by Wood Crib Fire. Proceedings of the Chinese Society of Electrical Engineering, 31, 192-197.

[7] Wu, T., Ruan, J., Chen, C. and Huang, D. (2011) Field Observation and Experimental Investigation on Breakdown of Air Gap of A.C. Transmission Line under Forest Fires. 2011 IEEE Power Engineering and Automation Conference (PEAM), 
Wuhan, 8-9 September 2011, 339-343.

[8] Li, P., Huang, D., Ruan, J., Wei, H., Qin, Z., Qiu, Z. and Chen, X. (2015) Study on the Dielectric Characteristics of Simulation Transmission Line Gap under Fire Conditions. Proceedings of the 2015 Annual Reports Conference on Electrical Insulation and Dielectric Phenomena, Ann Arbor, MI, 18-21 October 2015, 233-236.

[9] Hirano, T. (1973) Breakdown Potential of Potassium Seeded Combustion Products. Combustion and Flame, 21, 231-240. https://doi.org/10.1016/S0010-2180(73)80027-6

[10] Xu, K.G. (2014) Plasma Sheath Behaviour and Ionic Wind Effect in Electric Field Modified Flame. Combustion and Flame, 161, 1678-1686. https://doi.org/10.1016/j.combustflame.2013.12.008

[11] Messerle, H.K., Sakuntala, M. and Trung D. (1970) Arc Transition in MHD Generator. Journal of Physics D: Applied Physics, 3, 1080-1088. https://doi.org/10.1088/0022-3727/3/7/312

[12] Mphale, K.M. and Heron, M.L. (2007) Plant Alkali Content and Radio Wave Communication Efficiency in High Intensity Savannah Wildfires. Journal of Atmospheric and Solar-Terrestrial Physics, 69, 471-484.

https://doi.org/10.1016/j.jastp.2006.10.014

[13] Chandra, A., Dahiya, R.P., Raju, G.V.R. and Gupta, R.G. (1980) Cathode Sheaths in Potassium Seeded MHD Combustion Plasma. Journal of Physics D: Applied Physics, 13, 1211-1219. https://doi.org/10.1088/0022-3727/13/7/016

[14] Letsholathebe, D. and Mphale, K. (2013) Microwave Phase Perturbation and Ionisation Measurement in Vegetation Fire Plasma. IET Microwaves, Antenna and Propagation, 7, 741-745. https://doi.org/10.1049/iet-map.2012.0468

[15] Mongalo, N.I. (2013) Peltophorun Africanum Sond [Mosetlha]: A Review of Its Ethnomedicinal Uses, Toxicology, Phytochemistry and Pharmacological Activities. Journal of Medicinal Plants Research, 7, 3484-3491.

[16] Aganga, A.A. and Mesho, E.O. (2008) Mineral Contents of Browse Plants in Kweneng District in Botswana. Agricultural Journal, 3, 93-98.

[17] Jenkins, B.M., Baxter, L.L., Miles, T.R. and Miles, T.R. (1998) Combustion Properties of Biomass. Fuel Processing Technology, 54, 17-46. https://doi.org/10.1016/S0378-3820(97)00059-3

[18] Wilk, R.D., Pitz, W.J., Westbrook, C.K., Addagarla, S., Miller, D.L., Cernansky, N.P. and Green, R.M. (1989) Combustion of N-Butane and Isobutane in an Internal Combustion Engine: A Comparison of Experimental and Modeling Results. Symposium (International) on Combustion, 23, 1047-1053. https://doi.org/10.1016/S0082-0784(06)80363-2

[19] Ševčik, L., Nguyen, H. and Petru, N. (2017) Design of Gas Burner for the Fire Intensity Testing of Segmental Doors. The 58th International Conference of Machine Design Departments, Prague, 6-8 September 2017.

[20] Gaydon, A.G. and Wolfhard, H.G. (1979) Flames: Their Structure, Radiation and Temperature. 4th Edition, Chapman and Hall, London.

[21] Raju, M.P. and Tien, J.S (2008) Modeling of Candle Burning with a Self-Trimmed Wick. Combustion Theory and Modeling, 12, 367-388. https://doi.org/10.1080/13647830701824171

[22] Hamins, A. and Bundy, M. (2005) Characterization of Candle Flames. Journal of Fire Protection Engineering, 15, 265-285. https://doi.org/10.1177/1042391505053163 
[23] Wang, Y., Nathan, G.J., Alwahabi, Z.T., King, K.D., Ho, K. and Yao, Q. (2010) Effect of a Uniform Electric Field on Soot in Laminar Premixed Ethylene/Air Flames. Combustion and Flame, 157, 1308-1315.

https://doi.org/10.1016/j.combustflame.2010.03.001 